Portland State University

PDXScholar

6-5-1972

\title{
Auditory and Visual Sensory Stores: a Recognition Task
}

James Barr Richardson

Portland State University

Follow this and additional works at: https://pdxscholar.library.pdx.edu/open_access_etds

Part of the Psychology Commons

Let us know how access to this document benefits you.

\section{Recommended Citation}

Richardson, James Barr, "Auditory and Visual Sensory Stores: a Recognition Task" (1972). Dissertations and Theses. Paper 1558.

https://doi.org/10.15760/etd.1557

This Thesis is brought to you for free and open access. It has been accepted for inclusion in Dissertations and Theses by an authorized administrator of PDXScholar. Please contact us if we can make this document more accessible: pdxscholar@pdx.edu. 
AN ABSTRACT OF THE THESIS OF James Barr Richardson for the Master of Arts in Psychology presented June 5, 1972

Title: Auditory and Visual Sensory Stores: A recognition Task.

APPROVED BY MEMBERS OF THE THESIS COMMITTEE:

$$
\text { Barry F. Anderson, Chairman }
$$

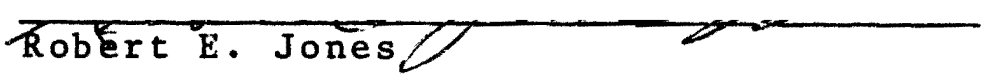

James A. Paulson

A probe-stimulus recognition technique was used to test hypothesized differences in visual and auditory sensory memory storage. Lists of alphabetical letters were presented visually or auditorially, each followed by a visual or auditory probe. Performance on the auditory lists was predicted to be better than on the visual 11sts. Moreover, auditory lists followed by a visual probe (AV) were expected to show a decrement in performance in comparison to auditory 11stauditory probe tasks (AA). Visual lists followed by an auditory probe (VA) were likewise expected to result in a decrement in performance in comparison to visual 1ist-visual probe tasks (VV). An hypothesis of performance ordering in the form $A A>A V>(V V, V A)$ was tested and supported. Delay periods of $1 / 2$ and $21 / 2$ seconds were used between presentation of the last item of the list and present- 
ation of the probe. It was hypothesized that the shorter. delay would substantially increase the probability of a correct response in the auditory list conditions as a function of the contribution of a preperceptual acoustic store. This hypothesis was also supported. Performance hypotheses in the form $A A>A V$ and $V V>V A$ for the $21 / 2$ second delay were not confirmed. The possibility of rehearsal was cited.

The results of this study support the memory models which distinguish between auditory and visual sensory stores with respect to length of decay. Information is made available longer from auditory sensory memory than from visual sensory memory and retrieval from these stores is facilitated when the probe item is in the same mode as the list. 


\title{
AUDITORY AND VISUAL SENSORY STORES:
}

\section{A RECOGNITION TASK}

\author{
By \\ James Barr Richardson
}
A thesis submitted in partial fulfillment of the requirements for the degree of


TO THE OFFICE OF GRADUATE STUDIES:

The members of the Committee approve the thesis of

James Barr Richardson presented June 5, 1972.

Barry T. Anderson

RobertE. Jones

James A. Paulson

APPROVED :

Robert E. Jones, Gead, Departhent of Psychology

David T. Clark, Dean of Graduate Studies

June 5,1972 
ACKNOWLEDGEMENTS

I would like to thank the members of my committee,

Barry Anderson, Bob Jones, and Jim Paulson, whose thoughtful criticism and advice helped guide this project from its conception to this paper. I would like to thank Robert Powloski and Gerald March for their friendship and support, and my fellow graduate students for helping to provide the supportlIve atmosphere needed for the completion of this study. 
TABLE OF CONTENTS

PAGE

INTRODUCTION.......................... 1

I MODALITY DIFFERENCES IN EARLY PROCESSING... 1

II SENSORY MODALITY DIFFERENCES IN SHORT-TERM MEMORY......................... 2

Free $\operatorname{Reca} 11 \ldots \ldots \ldots \ldots \ldots \ldots \ldots \ldots$

Probe Techniques............... 3

III THE PROBLEM.................... 4

METHOD .............................. 8

I DESIGN........................ 8

I $\quad$ sUbJects....................... 8

III PROCEDURE...................... 8

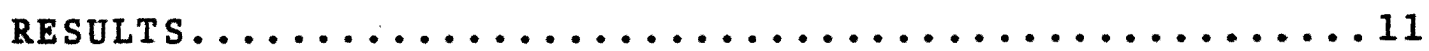

DISCUSSION ............................. 13

REFERENCES............................ 16 


\section{LIST OF FIGURES}

\section{FIGURE}

PAGE

I Probability of Correct Response in the

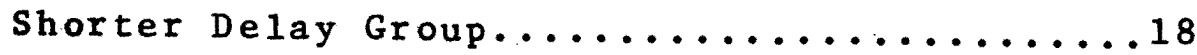

II Mean Error per Subject for al1 Treaments....19 


\section{INTRODUCTION}

In recent years, there has been general agreement as to the stages of processing involved in human memory. This consensus is reflected in a new class of memory models which view human memory as a complex of interacting stages. This approach is frequently referred to as Human Information Processing and opposes the older, simpler view of memory as being a unitary mediator between stimuli and responses. While a good deal of agreement has been found about a number of essential features, only a bare framework of empirical evidence is currently available to test the theoretical demands of these various models.

This paper is concerned with testing predictions and providing data with respect to auditory and visual differences in the first of the above mentioned stages, preperceptual storage.

\section{MODALITY DIFFERENCES IN EARLY PROCESSING}

Processing begins when information of sufficient energy Is transformed by the sensory system into physiological data. These data, in their transformed form, are stored briefly in sensory memory. This brief storage allows for feature extraction and organization. For vision, the duration of this starage has been estimated to be on the order of a small fraction of a second. (Averbach and sperling, 1961; Sperling, 1963). For audition, the maximum useful life of this store is. estimated to be on the order of two seconds (Morton, 1970). 
Since the auditory system is mainly concerned with the temporal properties of auditory stimuli, one would expect just such a difference.

The newly encoded data are then transferred to a different storage system, most often called short-term memory. Further processing of the data, such as rehearsal and organIsation, substantially increases storage length in short-term memory. Although it is disputed as to whether short-and long-term memory are distinguishable, everyone accepts the need for the existence of preperceptual storage (Morton, $1970)$

II. SENSORY MODALITY DIFFERENCES IN SHORT-TERM MEMORY

\section{Free Recal1}

Studies of short-term memory have relied heavily on recall as a measure of retention. This is especially true of those studies concerned with the serial organization of memory. Such studies have shown that the nature of serial organization is influenced by the order in which items are emitted In recall (Deese, 1957; Murdock, 1963; Tulving and Arbuckle, 1963, 1966) as well as other variables (Posner, 1963;

Postman, 1964). When a subject is not restricted to the order of recall the most recent items are produced first and best (Murdock, 1962; Postman and Phillips, 1965; Baddaley, 1968). These studies did not test for modality differences. However, several free recall studies show differences 
In the recency effect which could be attributed to modality differences in preperceptual storage. Murry (1966) presented elght-consonant lists visually, with instructions either to read the letters silently as they appeared or to read them aloud. Vocalization facilitated recall, especially on the terminal items. Conrad and Hull (1968) have recently confirmed this effect of vocalization at presentation upon visually presented 1ists. These data make it possible to conclude that the essential difference between the two presentation modes is not the original source of the stimulus information, but rather whether or not auditory traces result from the information processing. Murry (1965) has shown that the overall advantage of vocalized rehearsal is negated in white noise unless the vocalization is of sufficfent amplitude to be audible to the subject.

\section{Probe Techniques}

The standard procedure in a probe technique is to present a list of items, then to present one of the items from the list (the probe) after a specific duration of time. The subject's task is usually to respond with the item which followed the probe in the 1ist. The probe technique makes it possible to test retention on any item and on any serial position (except, of course, the first) without previous response items confounding the retention measure. With this technique it is also possible to control more accurately the amount of time from presentation of the item to its recall. 
In general, probe techniques yield the same shape serial position curves as free recall and structured free recall tasks, except that the position of worse recall is earlier In the 1ist (Murdock, 1960).

Using the probe technique described above, Murdock $(1966 \mathrm{~b}, 1967) \cdot$ has shown differences in retrieval ability from STM resulting from mode of presentation of verbal material. He found that with auditory presentation there was a larger recency effect, but a larger primacy effect with visual presentation. The larger recency effect with audition fits well with present models of preperceptual storage contributions. Since subjects were allowed to vocalize with presentation of the visual list, it is difficult to interpret the visual primacy effect. Although it is known that aspects of subvocalization (articulation, for example) do not affect preperceptual storage, it is not known whether such a contribution could affect STM in serial learning.

\section{THE PROBLEM}

Traditional recall measures raise the problem of removing or assessing the influence of order of recall on $\underline{s}^{\prime} s$ output from memory and on the distribution of memory-trace strengths which are presumed to underlie that output. Probe recall techniques have eliminated some of these problems by asking for stored items occupying a specific position within the stimulus organization. If one tries to assess these posItion differences by the conventional recall procedure, one $1 s$ getting only those responses which clearly exceed $\underline{S}^{\prime} s$ 
response criterion. Under these conditions probability measures tell us very little about the strength. (or even presence) of memory traces. A more appropriate solution might be to go back to recognition-type measures for STM (Murdock, 1966b).

Further, in the study of modality differences, probe techniques have invariably involved transformation of the visually presented material into a verbal component for response. Any auditory advantages thus far demonstrated in the 1iterature could therefore be explained by the assertion that auditory stimuli are more easily encoded for verbal response than visual stimuli. Evidence that mode of presentation and mode of response interact has been found by Brooks (1968).

For these reasons a recognition-probe technique has been used in this study. Earlier studies using a recognitionprobe technique have shown the potent effects of recency on short-term recognition memory. It is the intent of this study to use these techniques to look at modality differences. Using probe delays of four, eight, or twelve seconds and the probe-stimulus technique, Jahnke and Erlich (1968) found that recognition rates appeared to drop most rapidiy for terminal items as delay increased. However, the shape of the serial position curve remained essentially unchanged by increasing delay. Unfortunately, delays of four seconds are well beyond the hypothesized length of efther visual or auditory preperceptual stores. This study uses two delay 
periods; one of .5 seconds and one of 2.5 seconds. The former would allow the probe to fall well within the hypothesized auditory sensory store and the latter would lie just outside the effective life of this store. Visual sensory storage is presumed not to be a contributor, even at the shorter delay.

It is also the purpose of this study to provide data on cross-modality probing and sensory memory. It is hypothesized that a probe of the same modality as the stimulus list will be easier to recognize than one of a different modality, especially for auditory lists at the very short (.5 sec.) delay period. In summary, this study wishes to deal with the following three questions:

1) It is already known that modality differences are present in recall of terminal items of a list. It is of Interest to know whether these are due only to response mode or actually reflect differences in preperceptual memory. The probe-stimulus recognition technique will test this.

2) The temporal extent of auditory preperceptual memory has been estimated to be on the order of two seconds. This study makes predictions based on this estimate. Specifically, the difference betwwen performance on the auditory and visual lists on the short delay are expected to be larger than the differences on the longer delay.

3) A task in which the stimulus list and probe Items are in the same modality would be presumed to be easier than when they are in different modalities, at least during 
that time when sensory storage is still active. This study will test that assumption. 


\section{METHOD}

\section{DESIGN}

To test the hypotheses, the following design was used: Subjects were nested under each of two probe delay conditions to which they were randomly assigned. Within delay conditIons, each $\underline{\mathrm{S}}$ received 14 lists with accompanying probes, under each of four treatments:

1) auditory list-auditory probe (AA)
2) auditory 1ist-visual probe
(AV)
3) visual list-visual prober
4) visual list-auditory probe

The two probe delay conditions were .5 and 2.5 seconds. Within each treatment, presentation order of the lists was randomized for each subject. Twenty-four of the subjects, thirteen female and eleven male, served at the .5 second probe delay. Twelve subjects, seven female and five male, served at the 2.5 second probe delay. Treatment presentation order was completely balanced for subjects in the .5 second delay group and randomized for, the subjects in the 2.5 second delay group.

\section{I SUBJECTS}

Thirty-six unpaid undergraduate volunteers, twenty female and sixteen male, served as subjects.

\section{PROCEDURE}

A stimulus list was composed of a sequence of eight 
letters selected randomly from one of two pools of twelve letters each. The pools were selected randomly, by computer, from the twenty-six letters of the alphabet, with the following constraints:

1) Pools were selected from the alphabet without replacement.

2) No one pool could contain two of the acoustically similar letters $\underline{B}, \underline{C}, \underline{D}, \underline{G}, \underline{P}, \underline{T}, \underline{V}, \underline{Z}$. This constraint was imposed in an effort to avold or reduce acoustic confusion of the type réported by Sperling and speelman (1970).

3) No one pool could contain any two letters with less than two distinguishable grapheme characteristics (e.g. $R$ and $P$ were excluded from the same pool, as were $Q$ and 0). This constraint was imposed in an effort to avoid or reduce visual confusion.

From these pools lists of eight letters each were chosen at random without replacement. Letter sequences corresponding to English words were eliminated. Lists were then assigned randomly to each of the four conditions until each condition contained 14 lists. Each possible probe position was assigned two lists, one of which was assigned a correct probe, the other an incorrect probe. A correct probe consisted of two letters from the list which were in the same immediate sequential order in the 1ist. An incorrect probe consisted of two letters from the 1ist, the second of which immediately preceeded the first in the 1ist.

The auditory lists and probes were spoken in a male 
volce with American pronunciation without any significant regional accent. The letters weres poken in time to a metronome heard from tape through earphones. They were recorded on magnetic tape and presented to subjects at approximately conversational speech intensity.

The visual lists and probes were presented on one of two small twelve-lamp one-plane projectors positioned at eye level approximately two feet in front of the subject. Letters appeared centered on the screen and were $1.5^{\prime \prime} \times 1.5^{\prime \prime}$ 1arge. Lists and probes were timed by a Massey Dickenson timed stepper and lamp drivers. Each presentation list was presented on one of the two projectors. If the probe was visual it also appeared on the same projector. One list presentation rate was used--two letters per second. The two probe items were presented at the same rate.

In all conditions the task of the subject was to respond "yes" if the two probe items followed in the same sequence in the list, and "no" if the probe items did not appear in the same sequence in the 1ist. Subjects were asked to respond as quickly as possible and were told to guess if uncertain. After the subject read the instructions the experimenter presented vocally a sample task. Care was taken to assure that every subject understood the directions before the experiment started. Separate instructions were given to each subject before each treatment. 


\section{RESULTS}

Errors were conted and summed over the last two serial positions for each treatment in each delay group. A distribution-free test statistic developed by Page (1963), referred to as the $L$ statistic, was used to test the null hypothesis $A A=A V=V V=V A$ versus the alternative hypothesis $A A>A V P(V V, V A)$ within the .5 second delay group. This statistic is based on ranks assigned within rows and is similar In computation to the Friedman 1-was ANOVA by ranks (this statistic is described in Bradley, 1968). The general idea behind this type of hypothesis test was to include the probe modality difference hypothesis, AA>AV within a test for presentation list differences (auditory presentation > visual presentation). The null hypothesis was rejected ( $L=652.5$, p .001). As can be seen in figure 1, differences of the order tested above appear only over the last two serial positions, that is, only on those items which would be expected to be in auditory sensory memory at the time of the probe.

To test whether the advantage predicted and shown above by the auditory list presentation would diminish significantly with a longer delay between the probe and list, a one-tailed t-test was used. The null hypothesis, $(A A+A V) .5-(V V=V A)$ $.5=(A A+A V) 2.5-(\nabla V+V A)_{2.5}$, was rejected $(t=2.05, p .025)$. Please refer to figure 2. Cross-modality differences in the 2.5 second delay group were tested and were found insignificant, although the data lie in the predicted direction. 
See Figure 2 . 
DISCUSSION

The results are quite straightforward and indicate that performance on a reocgnition task reflects presentation modality differences on the last few serial positions. Figure 1 11lustrates most clearly the advantage of auditory presentations over visual presentations for the short delay groups. It should be noted from Figure 2 that, in the shorter delay, the differences within presentation modes are greater for the auditory list than for the visual lists. This is to be expected because, presumably, the visual preperceptual memory is not a contributor, even at the shorter delay. The larger differences within the auditory lists, where the mean error per subject is twice as high for the cross-modal probe, reflect preperceptual storage contributions. See Figure 2 .

It can be seen in Figure 2 that mean errors per subject in the 2.5 second delay reflect little difference between the treatments. This would seem to argue against modal specificity in STM. In any case, contribution of the preperceptual auditory store was shown to weaken considerably over time. Switching of attention could have played some role in those lists probed across modes. Such an explanation seems unlikely, as significant differences were apparent only over short delays between 1 ist and probe.

Eurthermore, the results of this study direct themselves to the kind of storage in short-term memory. Basica11y, there seem to be two contrasting possibilities. One 
Is that all $\underline{\mathrm{S}}$ is doing in the experiment is marking or tagging items stored years before for later retrieval. The other is that some sort of "experimental record" (Penfield and Perot, 1963) is laid down during presentation. The present data seem more consonant with the latter model than the former. The main reason is this: If the function of the presentation was merely to tag, then why does it make a difference how the Items are tagged? Moreover, if it is argued that some tags (auditory) are more visible than others, why is this not the case throughout the list (See Figure 1) and why would a delay affect -some tags more than others? Murdock (1967) mentions tagging as a plausible possibility of a memory system operating without modality differentiated storages. The data in this study quite clearly indicate memory differences attributable to list and list-probe modality differences.

In general, the data support the previous contention that, in short-term memory measured by a recognition task, retrleval can be from a preperceptual sensory store. Modality differences can be large, and together with crossmodality probe findings, seem to argue against the notion that items presented serlally are merely tagged for later retrieval. In cross-modal probing, switching of attention may be involved, but it alone cannot explain the results obtalned. The possibility of rehearsal of the list between the list and presentation of the probe must also be mentioned. However, rehearsal of auditory lists has been shown to be easier than rehearsal of visual lists. Despite this, 
probing auditory lists on the short delay was shown to be significantly superior to probing after the longer delay. One could only expect that without rehearsal the modality differences would have been even smaller at the longer delay. 


\section{REFERENCES}

Averbach, E., \& Sperling, G. Short-term storage of information in vision. In C. Cherry (Ed.), Information theory. London and Washington, D.C.: Butterworth, 1961.

Baddaley, A. D. Delay and the digit probe. Psychonomic Sclence, $1968,12,147-148$.

Bradley, J. A. Distribution-free statistical tests. New Jersey: Prentice Ha11, 1968 .

Brooks, M. Spatial and Verbal Components of the act of reca11. Canadian Journal of Psychology, 1968, 22, 349-369.

Conrad, R. \& Hull, A. J. Input modality and the serial position curve in short-term memory. Psychonomic Science, $1968,10,135-136$.

Deese, J. Serial organization in the recall of disconnected items. Psychologica1 Reports, 1957, 3, 577-582.

Jahnke, J. C. \& Erlick, D. E. Delayed recognition and the serial organization of short term memory. Journal of Experimenta1 Psychology, 1968, 77, 641-647.

Morton, J. A functional model for memory. In D. A. Norman (Ed.), Models of human memory. New York: Academic Press, 1970 .

Murdock, B. B. The serial position effect of free recall. Journa1 of Experimenta1 Psychology, 1962, 64, 482-488.

Murdock, B. B. Interpolated recall in short-term memory. Journa1 of Experimenta1 Psychology, 1963, 66, 525-532.

Murdock, B. B., Jr. Visual and auditory stores in short-term memory. Quarterly Journa1 of Experimental Psychology, 1966 (a), 18, 206-211.

Murdock, B. B., Jr. The criterion problem in short-term memory. Journal of Experimental Psychology, $1966(\mathrm{~b})$, $72,317-324$.

Murdock, B. B., Jr. Auditory and visual stores in short-term memory. Acta Psychologica, 1967, 27, 316-324.

Murdock, B. B., Jr. Serial order effects in short-term memory. Journal of Experimental Psychology, 1968, 76, (Monograph Supplement 4, Part 2). 
Murry, D. J. The effect of white noise on the recall of vocalized lists. Canadian Journal of Psychology, $1965,19,333-345$.

Murry, D. J. Vocalization-at-presentation and immediate recal1, with varying recall methods. Quarterly Journal of Experimental Psychology, $19 \overline{66,18,9-18 . ~}$

Page, E. G. Ordered hypotheses for multiple treatments: A significance test for linear ranks. Journal of

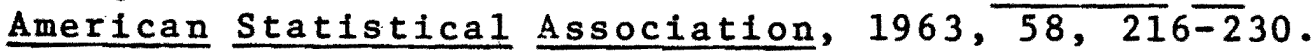

Penfleld, W., \& Perot, P. The brain's record of auditory and visual stimulus. Brain, 1963, 86, 595-696.

Posner, M. I. Immediate memory in sequential tasks. Psychologica1 Bulletin, 1963, 60, 333-349.

Postman, L. short-term memory and incidental learning. In A. W. Melton (Ed.), Categories of Human Learning. New York: Academic Press, 1964.

Postman, L., \& Phillips, L. W. Short-term temporal changes in free recall. Quarterly Journal of Experimental Psychology, $1965,17,132-138$.

Sperling, G. A model for visual memory tasks. Human Factors, $1963,5,19-31$.

Sperling, G., \& Speetlman, R. G. Acoustic similarity and auditory short-term memory: Experiments and a model. In D. A. Norman (Ed.), Models of Human Memory. New York: Academic Press, 1970 .

Tulving, E., Arbuckle, T. Y. Sources of intratrial interference in immediate recall of paired associates. Journal of Verbal Learning and Verbal Behavior, 1963, $1,321-334$.

Tulving, E., \& Arbuckle, T. Y. Input and output interference in short-term associative memory. Journal of Experimenta1 Psychology, 1966, 72, 145-150. 


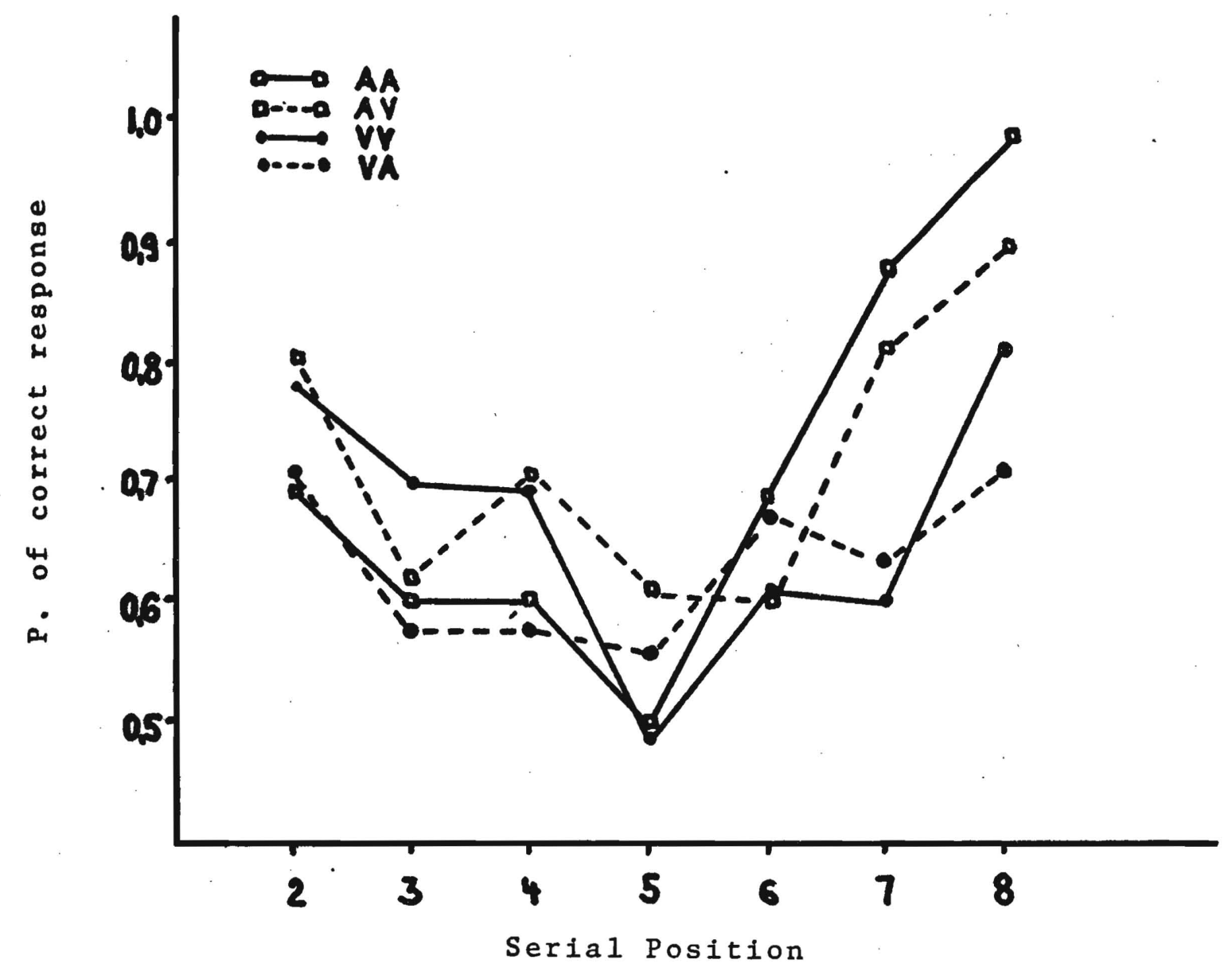

Figure 1. Probability of a correct response across serial positions in the . 5 second delay group. 


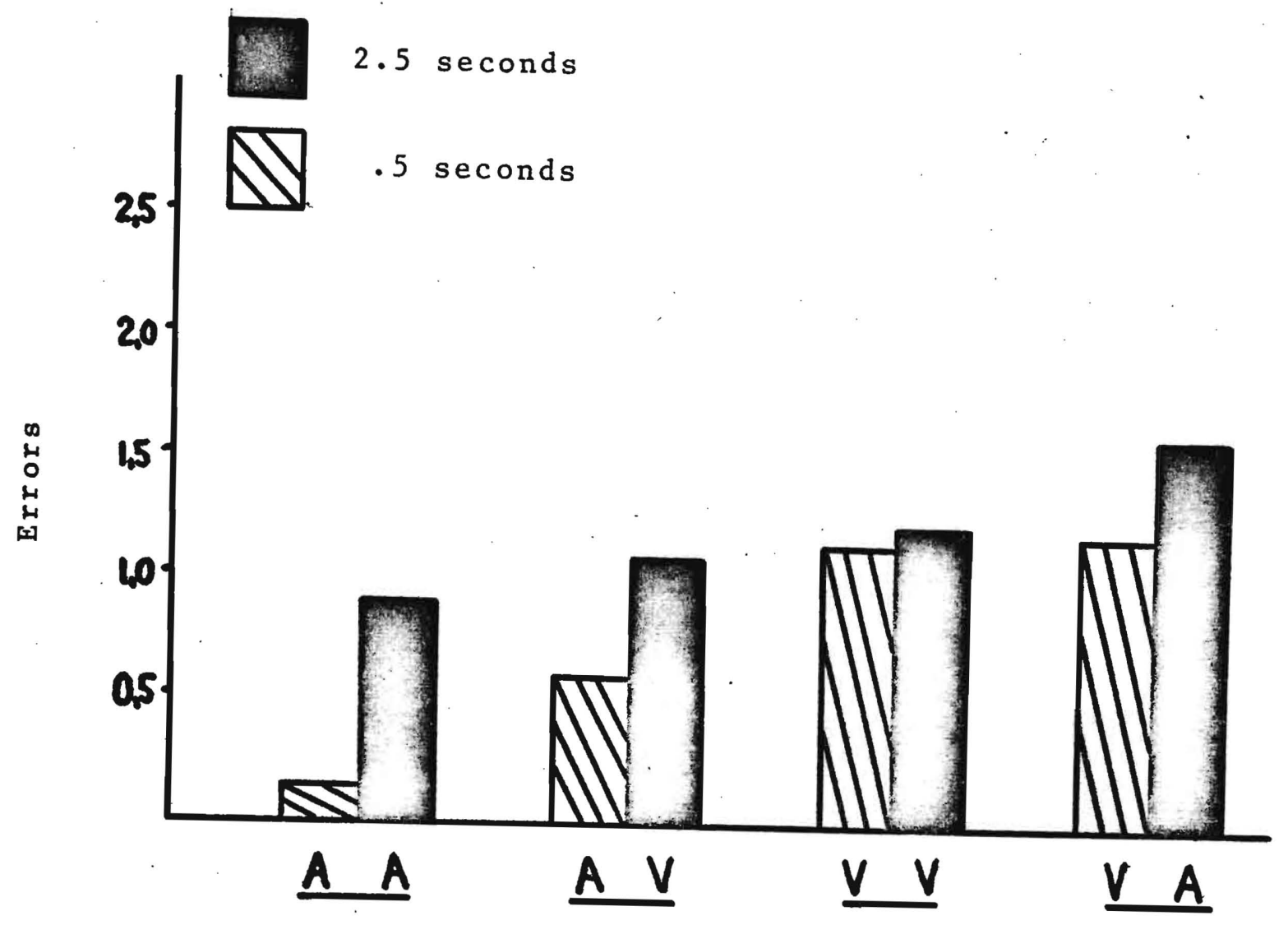

Figure 2. Mean errors per subject for all treatments. $V V$ - visual-visual; 